\title{
Nonsurgical Management of the Brain's Trauma in the University Hospital of Brazzaville
}

\author{
Hugues Brieux Ekouele Mbaki ${ }^{*}$, Marie Elombila², Olivier Brice Ngackosso1, Brice Sinclair Kinata ${ }^{1}$, \\ Léon Boukassa1, Gilbert Fabrice Otiobanda²
}

${ }^{1}$ Department of Surgery, University Hospital of Brazzaville, Brazzaville, Congo

${ }^{2}$ Department of Intensive Care, University Hospital of Brazzaville, Brazzaville, Congo

Email: *brieux_1@yahoo.fr

How to cite this paper: Mbaki, H.B.E., Elombila, M., Ngackosso, O.B., Kinata, B.S., Boukassa, L. and Otiobanda, G.F. (2016) Nonsurgical Management of the Brain's Trauma in the University Hospital of Brazzaville. Neuroscience \& Medicine, 7, 157162.

http://dx.doi.org/10.4236/nm.2016.74016

Received: October 17, 2016

Accepted: December 5, 2016

Published: December 8, 2016

Copyright $\odot 2016$ by authors and Scientific Research Publishing Inc. This work is licensed under the Creative Commons Attribution International License (CC BY 4.0).

http://creativecommons.org/licenses/by/4.0/

\begin{abstract}
The aim of this study was to evaluate the medical management of traumatic brain injury. We performed a retrospective and descriptive study during the period from $1^{\text {st }}$ January 2014 to $31^{\text {st }}$ December 2015 (24 months), into the surgical department of the University Hospital of Brazzaville. 167 cases of non-operated traumatized brain have been identified. The average age was 29.84 years. The sex ratio was 8.82 . Accidents on public roads were responsible for injury in $88.2 \%$ of the cases. $46.71 \%$ of patients had a moderate traumatic brain injury while $10.18 \%$ had a severe traumatic brain injury. Radiological evaluation was highlighted for the brain contusion in $52.09 \%$ of the cases. Tracheal intubation and ventilation were completed only in 6 out of the 17 cases of severe traumatic brain injury. Prevention of post-traumatic seizure was performed with the use of phenobarbital or sodium valproate. Mannitol was used for its osmotic properties. The outcome was favorable in $55.68 \%$ of the cases. The most common complications were pulmonary infections, persistent neurological disorders, urinary infection and hyponatremia. Mortality was recorded at $13.77 \%$. Nonsurgical management of traumatic brain injury involves an expansion of the ventilatory assistance indication at all severe traumatic brain injuries, the fight against infectious complications and ionic monitoring.
\end{abstract}

\section{Keywords}

Nonsurgical Traumatic Brain Injury, Morbidity, Brazzaville

\section{Introduction}

Traumatic brain injuries are a major cause of morbidity and mortality in children and young adults, responsible for hospital stay and high cost of care [1]. The knowledge on 
the pathophysiology allowed us to issue recommendations in the management of traumatic brain injury [2]. These recommendations are of surgical order among many therapeutic tools, with indications more or less codified in the order of less than $10 \%$. Management of severe traumatic brain injury is involved by the progress of neuroradiology and reanimation. Association of primary and secondary lesions requires a multidisciplinary team made of urgentist, anesthesist, radiologist and neurosurgeons [3]. This study that the aims were to assess the management of head injuries apart from a surgical recommendation in Brazzaville (Congo), presented poor practice conditions in sub-Saharan countries.

\section{Material and Methods}

We performed a descriptive and retrospective study, during the period from $1^{\text {st }}$ January 2014 to $31^{\text {st }}$ December 2015 (24 months), into the surgical department of the University Hospital of Brazzaville which was the only tertiary center in the country with a frequency of 225 patients admitted per year. We included patients hospitalized for management of a traumatic brain injury. We have excluded the case in which the radiological data (scanner) were absent, cases of refusal of surgery, multiple trauma cases that were operated for an associated lesion other than head trauma. This study was performed in observance of conditions of local ethical committee. The parameters evaluated were clinical, diagnostic, treatment and outcome. Collection of data was performed from hospital register and treated in Excel 14.2.0 (120402).

\section{Results}

\subsection{Studied Population}

During the period from January 2014 to December 2015, 200 cases of traumatic brain injury were recorded. Of these patients, 175 cases (87.5\%) were not operated; among non-operated patients, eight cases were excluded from our study (one case of epilepsyrelated trauma dating back to 2012, five cases in which the scan was not performed, one case operated for cervical spine trauma and one refusal of surgery). Finally, 167 cases representing $83.5 \%$ of patients admitted for head injuries were recorded for this study.

\subsection{Anthropometric Characteristics}

The average age was 29.84 years, with extremes ranging from 2 to 84 years. We recorded 150 men against 17 women, a sex ratio of 8.82 .

\subsection{Clinical Aspects}

Table 1 below indicates clinical variables of patients.

\subsection{Radiological and Diagnostic Aspects}

On admission to the emergency, X-ray of cervical spine was performed in 80 patients (47.90\%), those of the thorax in 66 patients $(39.52 \%)$, those of the basin in 4 patients (2.39\%). The Cranioencephalic CT-scan was performed in 152 patients (91.01\%), mag- 
netic resonance imaging was performed in 15 patients (8.99\%), following a breakdown of the scanner. Table 2 shows different lesions found in CT-scan and magnetic resonance imaging.

\subsection{Therapeutic Aspects}

Among 17 cases of severe traumatic brain injury, 11 were admitted to intensive care and the other 6 in the surgery department for lack of space available in the single intensive care unit in the hospital. Of the 11 patients admitted to intensive care, the orotracheal intubation and ventilatory, with sedation using midazolam and fentanyl support was performed in 6 patients. Benzodiazepines were used for sedation and midazolam was used for hemodynamic brain benefit. Morphine was used for analgesia. No tracheotomy was performed in the aftermath of the oro-tracheal intubation.

Anti-epileptic treatment was administered in 8 cases that convulsed; we used

Table 1. Clinical characteristics of patients in our series.

\begin{tabular}{ccc}
\hline & & $\mathbf{n}(\%)$ \\
\hline Antecedents & Substance addiction & $33(19.76)$ \\
& Diabetes & $04(02.39)$ \\
Circumstances & Hypertension & $06(03.59)$ \\
& Public road accident & $147(88.02)$ \\
Neurological examination & Assaults, falls & $20(11.98)$ \\
& Glasgow coma scale (GCS) & \\
& Average $=11$ & $17(10.18)$ \\
& $3-8$ & $78(46.71)$ \\
Related injuries & $9-12$ & $72(43.11)$ \\
& $13-15$ & $08(04.79)$ \\
& Seizures & $21(12.57)$ \\
& Neurological deficit & $12(07.18)$ \\
& Thoracic & $09(05.38)$ \\
\hline & Cervical spine & $18(10.77)$ \\
& Orthopedic & Average $=4$ days $(45$ minutes to 9 days $)$ \\
\hline
\end{tabular}

Table 2. Encephalic lesions in initial imaging.

\begin{tabular}{cc}
\hline & $\mathbf{n}(\%)$ \\
\hline Contusions & $87(52.09)$ \\
Subarachnoid hemorrhage & $30(17.96)$ \\
No lesion in CT-scan & $28(16.76)$ \\
Acute Subdural hematoma & $16(09.58)$ \\
Pneumocephalus & $13(07.78)$ \\
Epidural hematoma & $08(04.79)$ \\
Diffuse cerebral edema & $04(02.39)$
\end{tabular}


phenobarbital. Immediate treatment of convulsion consisted of the administration of the bolus of diazepam. The prevention of post-traumatic seizure was used in 66 patients (39.52\%), the indications were cortical brain contusion, diffuse cerebral edema, pneumocephalus, acute subdural hematoma, subarachnoid hemorrhage, epidural hematoma and lower GCS or equal to 10. This prevention was not systematic; we used phenobarbital and sodium valproate.

Mannitol 20\% was administered in 9 patients with severe traumatic brain injury, including 3 patients in oro-tracheal intubation.

Heparin was administered to all patients in the series, at $0.4 \mathrm{ml}$ per day by subcutaneous injection, from the $24^{\text {th }}$ post-traumatic hour.

Proton-pomp inhibitor was systematic.

\subsection{Evolution}

Evolution was quickly favorable in 93 patients (55.68\%), with a normal GCS, oral feeding, and absence of neurological deficit. The average hospital stay for these patients was 5 days.

Evolution was marked by complications in 51 patients (30.53\%). Table 3 shows the patients in our series by types of complications.

The average hospital stay for these patients was 16 days.

23 patients of the series died (13.77\%) during the study period. Death was due to a complicated respiratory infection as part of a disturbance of consciousness in 16 patients, 5 cases of neurological distress, 2 cases of severe hyponatremia.

\section{Discussion}

This was a retrospective study, limited in the collection of data from patients after hospitalization, in the difficulty to join them across the country. In addition, an analytical work could show the influence of GCS in clinical evolution of patients; a comparison between operated and non-operated patient could give us more information.

The management of severe brain trauma involves control of haematosis by tracheal intubation and ventilatory support, with continuous sedation [3] [4]. In our series, 6 patients in this case were not supported in the intensive care unit because of the lack of

Table 3. Hospital morbidity.

\begin{tabular}{cc}
\hline & $\mathbf{n}(\%)$ \\
\hline Pulmonary infection & $24(47.06)$ \\
Disorders of consciousness or persistent agitation & $13(25.50)$ \\
Urinary infection & $06(11.76)$ \\
Hyponatremia & $06(11.76)$ \\
Decompensated diabetes & $01(01.96)$ \\
Hypernatremia & $01(01.96)$ \\
TOTAL & $51(100)$ \\
\hline
\end{tabular}


space; among the 11 patients admitted to intensive care, 6 underwent intubation and ventilation. Sedation goals for cerebral protection control of intracranial pressure and facilitation of care [5].

Preventive treatment of seizures was administered in 66 patients (39.52\%); Van Haverbeke et al. [6] initiated this treatment in $35.3 \%$ of cases in patients treated for severe head trauma. Post-traumatic seizures are classified according to time of occurrence [7] in immediate (first 24 hours), early (within a week) and late (over a week). Their frequency is estimated between $5 \%$ and $7 \%$; it increases with the severity of the trauma (11\%), and more to trauma by penetrated objects (35\% - 50\%) [8]. Phenytoin is the recommended first-line molecule; carbamazepine is more effective in the early and late seizures [9]. In our series, the choice fell on phenobarbital and sodium valproate for reasons of commercial availability and affordability.

Mannitol [10] was used for its osmotic properties; the recommended dose is 0.5 - 1 $\mathrm{g} / \mathrm{kg}$ in 20 minutes. It improves cerebral perfusion pressure and microcirculation. However, its use is preferable when the blood-brain barrier is intact. The hypertonic saline [11] has equivalent or superior effects to mannitol, especially when hemorrhagic shock is associated; but it was not used in our series by lack of availability.

In a global subsaharian's series (operated and non-operated), Fatigba et al. [12] found 755 cases of traumatic brain injury, a favorable change in $89.2 \%$ of cases, regardless of morbidity. The acquired pneumonia is common complications, especially in severe traumatic brain injury with mechanical ventilation [12]. The most frequent complications are hydroelectrolytic disturbs; hyponatremia was most frequent in our series (11.76\%), and would be related to salt loss syndrome or inappropriate antidiuretic hormone secretion [13].

Hospital mortality in traumatic brain injury is variable depending on the series; they range from $8.5 \%$ to $38 \%$ [14] [15] [16] [17]. In our study, the mortality of $13.77 \%$ for deaths occurred during the study period. It is linked to neurological and infectious complications.

\section{Conclusion}

Nonsurgical brain injuries are the most common; cerebral contusions in intracranial lesions are predominant. Their care involves preventing secondary brain aggression of systemic origin which is dominated in our series by respiratory complications providers of infection and electrolyte disturbances. The management of severe head trauma involves an expansion of ventilatory assistance indications in all cases of severe traumatic brain injury. Prevention of post-traumatic seizures and the use of osmotic remain to be evaluated in context of our study.

\section{References}

[1] Mac Kenzie, E.J., Siegal, J.H., Shapiro, S., Moody, M. and Smith, R.T. (1988) Functional Recovery and Medical Costs of Trauma: An Analysis by Type and Severity of Injury. Journal of Trauma-Injury Infection \& Critical Care, 28, 281-297.

https://doi.org/10.1097/00005373-198803000-00003 
[2] Brain Trauma Foundation, American Association of Neurological Surgeons, Congress of Neurological Surgeons (2007) Guidelines for the Management of Severe Traumatic Brain Injury. Journal of Neurotrauma, 24, S1-S106. https://doi.org/10.1089/neu.2007.9999

[3] Agence Nationale d'accréditation et d'évaluation en santé. Recommandations (1999) Early Management of Severe Traumatic Brain Injury. Guidelines for Clinical Practice. Annales Françaises d Anesthésie et de Réanimation, 18, 15-22.

https://doi.org/10.1016/S0750-7658(99)80106-3

[4] Bouhours, G., Ter Minassian, A. and Beydon, L. (2006) Severe Head Injury: Initial Management. Réanimation, 15, 552-560. https://doi.org/10.1016/j.reaurg.2006.10.004

[5] Leone, M., Visintini, P., Alliez, J.R. and Albanese, J. (2006) What Sedation for Prevention and Treatment Secondary Brain Insult? Annales Françaises d Anesthésie et de Réanimation, 25, 852-857. https://doi.org/10.1016/j.annfar.2006.03.012

[6] Van Haverbeke, L., Deraedt, S., Thevenin-Lemoine, B., Joly, J., Weiss, J.J., Fourgon, R. and Trutt, B. (2004) Severe Head Trauma in Adults: Early Management in the Île-de-France. Revue Médicale de I Assurance Maladie, 35, 19-25.

[7] Teasell, R., Bayona, N., Lippert, C., Villamere, J. and Hellings, C. (2007) Post-Traumatic Seizure Disorder following Acquired Brain Injury. Brain Injury, 21, 201-214. https://doi.org/10.1080/02699050701201854

[8] Yablon, S.A. (1993) Posttraumatic Seizures. Archives of Physical Medicine and Rehabilitation, 74, 983-1001.

[9] The Brain Trauma Foundation. The American Association of Neurological Surgeons. The Joint Section on Neurotrauma and Critical Care (2000) Role of Antiseizure Prophylaxis following Head Injury. Journal of Neurotrauma, 17, 549-553. https://doi.org/10.1089/neu.2000.17.549

[10] Foster, N. and Engelhard, K. (2004) Managing Elevated Intracranial Pressure. Current Opinion in Anaesthesiology, 17, 371-376. https://doi.org/10.1097/00001503-200410000-00004

[11] Bayir, H., Clark, R.S. and Kochanek, P.M. (2003) Promising Strategies to Minimize Secondary Brain Injury after Brain Trauma. Critical Care Medicine, 31, 112-117. https://doi.org/10.1097/00003246-200301001-00016

[12] Piek, J., Chesnut, R.M., Marshall, L.F., van Berkum-Clark, M., Klauber, M.R., Blunt, B.A., et al. (1992) Extracranial Complications of Severe Head Injury. Journal of Neurosurgery, 77, 901-907. https://doi.org/10.3171/jns.1992.77.6.0901

[13] Trouiller, P. and Mantz, J. (2016) Early Management of Traumatic Brain Injury. La Lettre du Neurologue, 10, 55-60.

[14] Fatigba, O.H. and Padonou, J. (2010) Epidemiology of Traumatic Brain Injuries in Parakou (BENIN). African Journal of Neurological Sciences, 29, 25-33.

[15] Emejulu, J.K. (2008) Epidemiological Patterns of Head Injury in a Newly Established Neurosurgical Service: One-Year Prospective Study. African Journal of Medicine and Medical Sciences, 37, 383-388.

[16] Coulibaly, Y., Mp, E., Diallo, A., Doumbia, D., Keita, M., Keita, A., Diallo, A., Diango, D.M., Ongoïba, N., Diallo, G. and Sidibe, S. (2004) Head Trauma in the Hopital du Point G: About 80 Cases. Mali Médical, 19, 3-4.

[17] Bahloul, M., Chelly, H., Ben Hmida, M., Ben Hamida, C., Ksibi, H., Kallel, H., Chaari, A., Kassis, M., Rekik, N. and Bouaziz, M. (2004) Prognosis of Traumatic Head Injury in South Tunisia: A Multivariate Analysis of 437 Cases. Journal of Trauma-Injury Infection \& Critical Care, 57, 255-261. https://doi.org/10.1097/01.TA.0000083004.35231.1E 
Submit or recommend next manuscript to SCIRP and we will provide best service for you:

Accepting pre-submission inquiries through Email, Facebook, LinkedIn, Twitter, etc. A wide selection of journals (inclusive of 9 subjects, more than 200 journals)

Providing 24-hour high-quality service

User-friendly online submission system

Fair and swift peer-review system

Efficient typesetting and proofreading procedure

Display of the result of downloads and visits, as well as the number of cited articles

Maximum dissemination of your research work

Submit your manuscript at: http://papersubmission.scirp.org/

Or contact nm@scirp.org 